\title{
A rare case of Parry Romberg syndrome with morphea
}

\section{Anbukarasi Ramalingam1, Ambujam Sreedevi²}

\author{
${ }^{1}$ Junior Resident, Department of Dermatology, Venereology and Leprosy, Indira Gandhi Medical College and Research \\ Institute, Puducherry - 605 009, India, ${ }^{2}$ Currently Professor and Head of the Department, Department of Dermatology, \\ Venereology and Leprosy, BCMC Hospital, St. Thomas Nagar, Kuttapuzha, Tiruvalla-689103, Kerala, India
}

Corresponding author: Dr. Anbukarasi Ramalingam, E-mail: dranbukarasi@gmail.com

\begin{abstract}
Parry Romberg syndrome or hemi facial atrophy is a rare neurocutaneous syndrome, characterized by slowly progressing atrophy primarily involving the skin, fat and connective tissue located on one side of the face. Morphea is an idiopathic sclerosis of skin with circumscribed scleroderma. Though prevalence of Parry Romberg syndrome is female predominant, we report the case of a boy with an unusual combination of the syndrome and morphea, face of the child showed asymmetry with hollowing of cheek due to atrophy. In addition, near the left para-umbilical region of abdomen a shiny, atrophic plaque characteristic of morphea was evident. Biopsy of the skin revealed atrophy of epidermis, increased collagen in dermis and atrophied dermal appendages, consistent with morphea. Blood tests, Ultrasound of abdomen and MRI-brain of the child were found to be normal. The boy was administered a typical immunosuppressant. The child and his parents were counselled for cosmetic intervention.
\end{abstract}

Key words: Parry Romberg syndrome; Progressive atrophy; Morphea; Sclerosis

\section{INTRODUCTION}

Parry Romberg syndrome (PRS) is characterized by slow progressing atrophy (prevalence: 1 in 7 lakhs) with female predominance. Primarily, PRS affects skin, fat, connective tissues and scarcely eye, brain or bones [1-3]. The PRS shows slow progression and stabilize over 3 to 5 years leaving behind a cosmetic defect. Etiology is unknown but it may be a disorder of sympathetic nervous system, trigeminal neuritis, a chronic autoimmune neurovasculitis, or a chronic infection with a neurotropic virus (herpes). Morphea is characterized by skin thickening with increased quantities of collagen in the indurative lesion and is subdivided into linear scleroderma, plaque morphea, deep morphea, bullous morphea, and generalized morphea $[4,5]$. The present case report is about the incidence of a rare occurrence of Parry Romberg syndrome along with morphea in a boy.

\section{CASE REPORT}

A five year old boy presented with shrinkage of the right side of cheek and skin changes over the abdomen. As per his mother's statement, the boy was quite normal until three years of age after which the right side of his face showed gradual shrinkage and a patch of dark and shiny area over the abdomen. His developmental milestones were normal. There was no history of seizure or migraine. There were no similar complaints among the family members or in the family history.

Clinical examination revealed a healthy boy with normal vital signs. Neurologist's, paediatrician's, dental surgeon's and ophthalmologist's opinions were sought to rule out or confirm other system involvement. He was alert and cheerful, with no signs of mental and psychological instability. Speech and hearing were normal. The face showed asymmetry with hollowing of cheek due to soft tissue atrophy (Fig. 1). There was a slight deviation of the angle of mouth towards the right side, when compared to the left. The Right ear was smaller than the left. Intra-oral examination revealed normal dentition for his age (dental age corresponded to chronological age). The right maxillary and zygomatic regions appeared atrophic (hypoplastic)

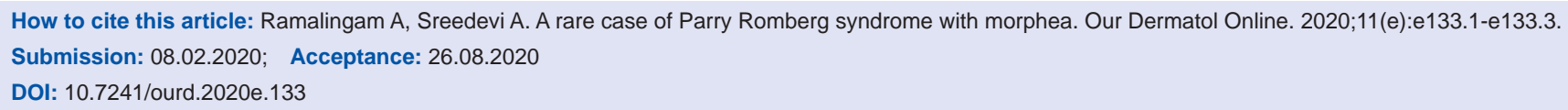


when compared to the left, due to the skeletal growth disturbance. His eyes were normal.

Over the left para-umbilical region of abdomen there was a shiny, atrophic scar-like oval plaque measuring $(5 \times 6) \mathrm{cm}$ (morphea). The rest of the skin and hair were normal. A provisional diagnosis of hemi facial atrophy (PRS) with morphea was made. His blood tests, Ultrasound abdomen and MRI- brain were found to be normal.

The left para umbilical skin biopsy (Fig. 2) revealed atrophy of epidermis, increased collagen in dermis and atrophied dermal appendages, consistent with morphea. Based on the clinical examination and the support of investigations, the diagnosis of Parry Romberg Syndrome in combination with localized morphea was made.

Having worked on the case, we counselled the child and his parents regarding the progressive nature of the disease, the need for reconstruction of bone and soft tissue (cosmetic intervention) upon stabilization of the disease and the need for schooling, despite the

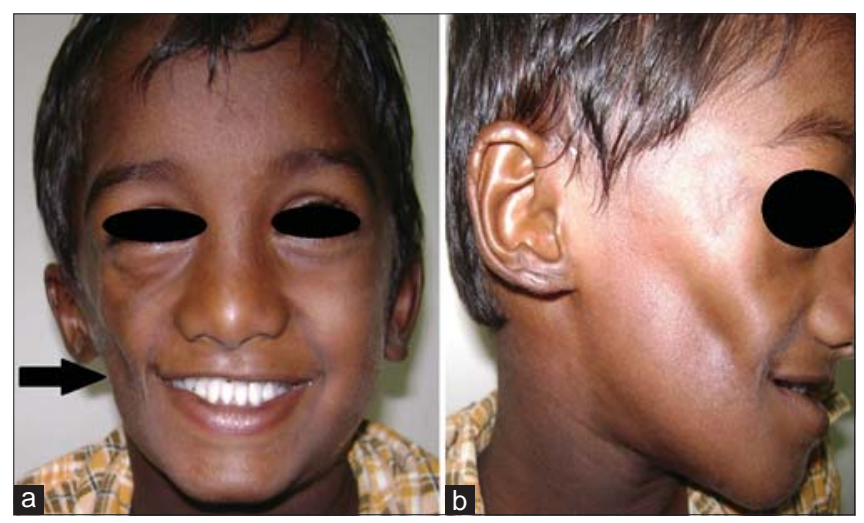

Figure 1: Clinical photographs showing facial defects (a) Skewing of mouth, (b) Hollowing of cheek due to soft tissue atrophy.

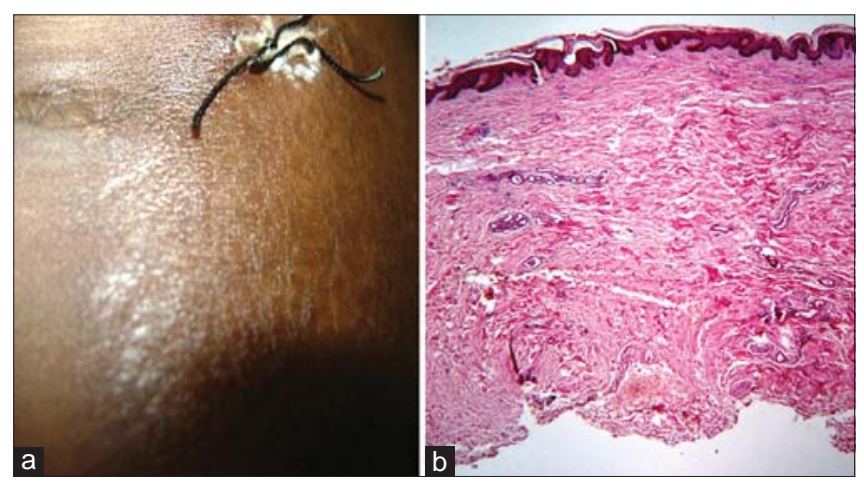

Figure 2: Clinical photographs showing morphea and histopathological analysis, (a) Morphoeic lesion in the abdomen, (b) Atrophy of epidermis (Olympus; hemotoxylin-eosin; 200x). deformity. Topical tacrolimus $(0.03 \%)$ was prescribed for the morpheic lesion.

\section{DISCUSSION}

The first manifestation of this disease is the increased or decreased pigmentation usually on the cheeks and lower jaw, occasionally involves one half of the body. Progressive atrophy gradually develops in the affected sites involving skin, sub cutis, muscle and bone. The eyes are often involved, loss of periorbital fat results in enophthalmos, ocular muscle paralysis, heterochromia of iris, ptosis, visual changes, but in the present case such degenerations were not observed. Horner's syndrome and dilated fixed pupil have been reported [6]. Severely affected patients have involvement of meninges and brain with a potential for contralateral seizure (Jacksonian), and trigeminal neuralgia [7]. The tongue and upper lip on involved side of face are usually atrophic. But in the present case, complications such as the above were not observed. The maxilla and mandible do not fully develop, resulting in malocclusion of teeth. Atrophy of salivary gland was not observed. CT or MRI brain of the boy in the present case was not indicative of complications. PRS stands without cure. Absence of sclerosis confirmed PRS in the present case from scleroderma of the 'en coup de sabre' type [8]. Morphea is a circumscribed scleroderma, with a marked atrophy of sub cutaneous fat and muscles and the plaque observed near the abdomen was its typical manifestation [9]. Triggering factors include trauma, BCG vaccine, Vitamin B-12 injection, radiation therapy, penicillamine, bromocriptine, measles, varicella and Borrelia burgdorferi infection but, parents of the child were unable to relate to the factors [10]. A pathogenic role for TGF- $\beta$ which stimulates fibroblasts to produce increased amounts of glycosaminoglycans, fibronectin, collagen. TGF- $\beta$ receptor expression in dermal fibroblasts is increased which may play a role in collagen-l over production in the present case [11]. Like PRS, morphea too has no cure. Treatment modalities available are: topical tacrolimus, topical calcipotriol, topical steroids, oral steroids, methotrexate etc., but none proved to be totally effective. In the present case $0.03 \%$ topical tacrolimus was administered [12].

\section{CONCLUSIONS}

PRS itself is rare (incidence) and a combination with morphea is rarer. But both stand without a cure. 
Beyond treatment for cosmetic disfigurement and other physical disability, yet another aspect that needs to be addressed is the psychological impact of the disease on the child and his parents.

\section{Consent}

The examination of the patient was conducted according to the Declaration of Helsinki principles.

The authors certify that they have obtained all appropriate patient consent forms. In the form the patient(s) has/have given his/her/ their consent for his/her/their images and other clinical information to be reported in the journal. The patients understand that their names and initials will not be published and due efforts will be made to conceal their identity, but anonymity cannot be guaranteed.

\section{REFERENCES}

1. Schultz KP, Dong E, Truong TA, Maricevich RS. Parry Romberg syndrome. Clin Plast Surg. 2019;46:231-7.

2. Segna E, Pucciarelli V, Beltramini GA, Sforza C, Silvestre FJ, Giannì AB, et al. Parry Romberg Syndrome and linear facial scleroderma: management in pediatric population. J Biol Regul Homeost Agents. 2017; 31(2 Suppl 1):131-8.

3. Patel H, Thakkar C, Patel K. Parry Romberg syndrome: A Rare entity. J Maxillofacial Oral Surg. 2010;9: 247-50.

4. Marsol IB. Update on the classification and treatment of localized scleroderma. Actas Dermosifiliogr. 2013;104:654-66.

5. Florez-Pollack S, Kunzler E, Jacobe HT. Morphea: Current concepts. Clin Dermatol. 2018;36:475-86.

6. Kanagalingam S, Miller NR. Horner syndrome: clinical perspectives. Eye Brain. 2015;7:35-46.

7. Vix J, Mathis S, Lacoste M, Guillevin R, Neau JP. Neurological manifestations in Parry-Romberg syndrome: 2 case reports. Medicine (Baltimore). 2015;94:e1147.

8. Kaliyadan F, Biswas K, Dharmaratnam AD. Progressive facial hemiatrophy - A case series. Indian J Dermatol. 2011;56;557-60.

9. Asano Y, Fujimoto M, Ishikawa O, Sato S, Jinnin M, Takehara K, et al. Diagnostic criteria, severity classification and guidelines of localized scleroderma. J Dermatol. 2018;45:755-80.

10. Aslam B, Nisar MA, Khurshid M, Farooq Salamat MK. Immune escape strategies of Borrelia burgdorferi. Future Microbiol. 2017;12:1219-37.

11. Biernacka A, Dobaczewski M, Frangogiannis NG. TGF- $\beta$ signaling in fibrosis. Growth Factors. 2011;29: 196-202.

12. Falanga V, Killoran CE. "Morphea" in Wolff K, Goldsmith LA et al. Fitzpatrick's Dermatology in General Medicine. Mc Graw Hill. 2008; 62:543-546.

Copyright by Anbukarasi Ramalingam, et al. This is an open access article distributed under the terms of the Creative Commons Attribution License, which permits unrestricted use, distribution, and reproduction in any medium, provided the original author and source are credited.

Source of Support: Nil, Conflict of Interest: None declared. 